\title{
Mitochondria-targeted therapies for acute kidney injury - ERRATUM
}

\section{Luis Carlos Tábara, Jonay Poveda, Catalina Martin-Cleary, Rafael Selgas, Alberto Ortiz and Maria D. Sanchez-Niño}

doi: 10.1017/erm.2014.14, Published by Cambridge University Press, 8 August 2014.

On page 13 of the above published article by Tábara et al., figure $4 \mathrm{~d}$ and g contain errors introduced during the production process. The corrected figure parts are published below.

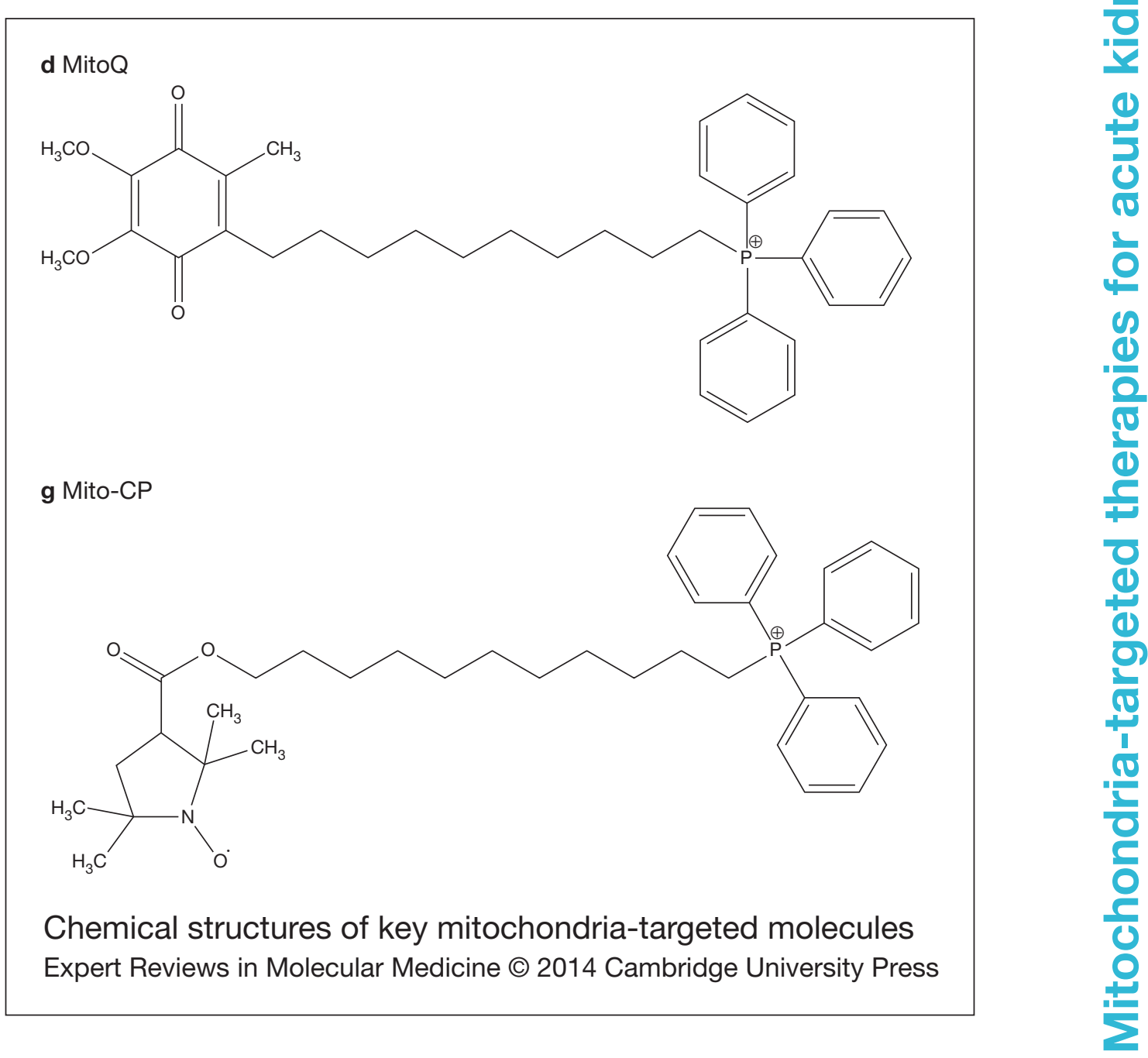

The Press apologises for these errors and for any inconvenience that may have been caused.

\section{Reference}

1 Tábara, L. C. et al. Mitochondria-targeted therapies for acute kidney injury. Expert Reviews in Molecular Medicine 16, published online 8 August 2014, doi:10.1017/erm.2014.14 